ISSN: 2354 - 1431

http://tckh.daihoctantrao.edu.vn/

\title{
Đa dạng tài nguyên cây làm thuốc tại khu bảo tồn thiên nhiên Na Hang, tỉnh Tuyên Quang
}

\author{
Nguyễn Thị Hải ${ }^{a, c}$,Trần Huy Thái $i^{b}$, Nguyễn Thế Cuờng ${ }^{b}$,Trần Thị Thanh Vân ${ }^{a}$ \\ ${ }^{a}$ Trưòng Đại học Tân Trào \\ ${ }^{b}$ Viện Sinh thái và Tài nguyên sinh vật - Viện Hàn lâm Khoa học và Công nghệ Việt Nam \\ ${ }^{c}$ Học viện Khoa học và Công nghệ-Viện Hàn lâm Khoa học và Công nghệ Việt Nam
}

\section{Article info}

Recieved:

03/7/2017

Accepted:

03/8/2017

\section{Keywords:}

Diversity;

Medicinal plants;

Na Hang;

Nature Reserve.

\begin{abstract}
In Na Hang Nature Reserve there was identified 647 medicinal plant species belonging to 137 families, 4 vascular divisions: Lycopodiophyta with 3 species, 2 families; Polypodiophyta with 20 species, 12 families; Pinophyta with 6 species, 4 families; Magnoliophyta with 618 species, 119 families. Concerning the diversity index: the family index: 4.72; the genus index: 1.49 ; the genus index/the family index: 3.16. In Na Hang Nature Rserve 10 families more species occupying $7.30 \%$ of the total families of medicinal plants with the total of species occupying $31.68 \%$ and $28.64 \%$ of the total of genus. The family more diverse is Asteraceae with 32 species, occupying $4.95 \%$ of the total of medicinal plants identified; following is Rubiaceae with 28 species (4.33\%), Euphorbiaceae with 26 species (4.02\%); Moraceae with 23 species (3.55\%); Cucurbitaceae, Verbenaceae with the same number of species 18 (2.78\%); Araceae with 17 species (2.63\%); Zingiberaceae with 16 species (2.47\%); Urticaceae with 15 species (2.32\%); and the last are families Poaceae of species $12(1.85 \%)$ in the total of species. 10 genera more diverse with 59 species ( $9.12 \%$ of the total of medicinal plants), Ficus (Moraceae) is more diverse with 15 species $(2.32 \%$ of the total of medicinal plants) and another genera with from 4 to 7 species. In Nature Reserve of Na Hang we have confirmed the distribution of 30 precious and rare and endangered species priorto the conservation: 23 species in Vietnam Red Data Book (2007): VU - 16 species, EN - 07 species; 17 species in Red List of medicinal plant of Vietnam (2006):VU - 10 species, EN - 6 species and CR - 01 species; 07 species in IUCN Red List (2014): LR - 06 species and VU - 01 species.
\end{abstract}

\section{1. Đặt vấn đề}

Khu Bảo tồn thiên nhiên (BTTN) Na Hang được thành lập theo Quyết định 274/UB-QĐ ngày 09 tháng 5 năm 1994 của Uỷ ban nhân dân tỉnh Tuyên Quang, nằm trên địa bàn các xã Khâu Tinh, Côn Lôn, Sơn Phú, Thanh Tương của huyện $\mathrm{Na}$ Hang, tỉnh Tuyên Quang; có tọa độ địa lý: $22^{0} 16^{\prime}-22^{0} 31^{\prime}$ vĩ độ Bắc; $105^{0} 22^{\prime}-105^{0} 29^{\prime}$ kinh độ Đông; với diện tích: $22.401,5$ ha. Địa hình dưới $300 \mathrm{~m}$ chiếm $30 \%$; $300 \mathrm{~m}$ đến $800 \mathrm{~m}$ chiếm $60 \%$; trên $900 \mathrm{~m}$ chiếm $10 \%$. Mùa đông nhiệt độ trung bình $15-20^{\circ} \mathrm{C}$, mùa hè nhiệt độ lên đến $30^{\circ} \mathrm{C}$ hoặc có thể hơn. Hệ thống sông ngòi chỉ ở mức trung bình, có hai con sông lớn chảy qua là sông Gâm (phía Tây Tát Kẻ) và sông Năng (phía Đông Na Hang). Mạng lưới sông ngòi nhỏ khá dày song chế độ nước lại không đều giữa các mùa trong năm. Lượng mưa cao nhất vào các tháng 6 và 7 (tương ứng
$316,9 \mathrm{~mm}$ và $314,0 \mathrm{~mm}$ ), thấp nhất vào các tháng 12,1 và $2(23,2 \mathrm{~mm} ; 25,6 \mathrm{~mm}$ và $28,1 \mathrm{~mm})[9]$.

Cho đến nay, tại khu BTTN Na Hang đã có một số công trình nghiên cứu, đánh giá về bảo tồn thực vật của Hill M. và Kemp N. [10, 11]. Theo Nguyễn Nghĩa Thìn \& cs. (2006) [6], hệ thực vật tại Khu Bảo tồn thiên nhiên $\mathrm{Na}$ Hang có 1162 loài thực vật, thuộc 604 chi, 159 họ của 4 ngành thực vật bậc cao có mạch; trong đó có 558 loài thực vật được ghi nhận có giá trị làm thuốc.Trần Huy Thái và cs $(2012)[7,8]$ về bảo tồn các loài Hoa tiên quí hiếm và đặc hữu trong chi Hoa tiên (Asarum) ở Na Hang, Tuyên Quang.Chưa có công trình nghiên cứu tổng thể nào về tài nguyên cây thuốc tại khu BTTN Na Hang, tỉnh Tuyên Quang. Vấn đề nghiên cứu, đánh giá tính đa dạng nguồn tài nguyên cây làm thuốc tại khu BTTN Na Hang, tỉnh Tuyên Quang nhằm đề xuất giải pháp bảo tồn và phát triển bền vững là vấn đề thời sự mang tính cấp thiết, có ý nghĩa khoa học và giá trị thực tiễn cao. 
2. Đối tượng, mục tiêu, nội dung và phương pháp nghiên cứu

\section{1. Đối tương nghiên cứu}

Các loài cây làm thuốc thuộc các ngành thực vật bậc cao có mạch tại khu Bảo tồn thiên nhiên $\mathrm{Na}$ Hang, tỉnh Tuyên Quang.

\subsection{Mục tiêu nghiên cúu}

Đánh giá được tính đa dạng cây làm thuốc tại khu Bảo tồn thiên nhiên Na Hang, tỉnh Tuyên Quang làm cơ sở cho việc bảo tồn và phát triển bền vững chúng.

\subsection{Nội dung nghiên cúu}

- Đánh giá tính đa dạng cây làm thuốc bậc ngành.

- Đánh giá tính đa dạng cây làm thuốc bậc dưới ngành (Đa dạng bậc họ, bậc chi).

- Đánh giá nguồn gen cây làm thuốc quý, hiếm có nguy cơ bị đe dọa tuyệt chủng.

\subsection{Phương pháp nghiên cúu}

\subsubsection{Phuơng pháp đánh giá tính đa dạng nguồn tài} nguyên cây thuốc

Để đánh giá tính đa dạng nguồn tài nguyên cây thuốc của khu BTTN Na Hang, dựa theo phương pháp đánh giá của Nguyễn Nghĩa Thìn (1997) [5], bao gồm:

- Đa dạng về các taxon cây thuốc ở bậc ngành.

- Đa dạng cây thuốc bậc họ, chi.

- Đa dạng nguồn gen bị đe dọa.

- Đa dạng về dạng thân.

Đánh giá đa dạng về các bậc taxon: tiến hành đánh giá tính đa dạng về thành phần loài của các taxon như sau:

+ Đánh giá đa dạng ở bậc ngành: số lượng, tỷ lệ phần trăm các họ, chi, loài của mỗi ngành.

+ Đánh giá đa dạng ở bậc lớp: số lượng, tỷ lệ phần trăm các họ, chi, loài của mỗi lớp trong ngành Mộc lan (Magnoliophyta).

+ Đánh giá chung bằng các chỉ số đa dạng: Chỉ số ho là số loài trung bình của mỗi họ; chi số chi là số loài trung bình của mỗi chi; số chi trung bình của một họ.

+ Các họ và các chi đa dạng nhất: Các họ và các chi nhiều loài nhất được lựa chọn làm nhóm đại diện, đánh giá mức độ đa dạng và thành phần của 10 họ và 10 chi đa dạng nhất.
Đánh giá về giá trị bảo tồn nguồn gen cây thuốc theo tiêu chí của Nghị định 32/2006/NĐ-CP [3], Danh luc đỏ cây thuốc (2006)[4], Sách đỏ Việt Nam (2007)[1], IUCN Red List (2014)[12]...

\subsubsection{Phwơng pháp đánh giá đa dạng dạng thân}

Chia dạng thân của các loài cây thuốc theo Tên cây rừng Việt Nam [2] thành:

+ Dạng cây thân gỗ: cây gỗ lớn, gỗ vừa, gỗ nhỏ.

+ Dạng thân bụi: cây bụi, nửa bụi, bụi trườn.

+ Dạng thân thảo: cây thảo 1 năm, cây thảo nhiều năm.

+ Dạng cây leo: cây thảo leo, bụi leo, cây gỗ leo.

\section{Kết quả nghiên cứu và thảo luận}

\section{1. Đa dạng nguồn tài nguyên cây thuốc tại khu Bảo tồn thiên nhiên Na Hang, tỉnh Tuyên Quang}

Kết quả nghiên cứu tại khu Bảo tồn thiên nhiên (BTTN) $\mathrm{Na}$ Hang, tỉnh Tuyên Quang đã xác định được 647 loài thực vật được ghi nhận sử dụng làm thuốc, thuộc 137 họ, 4 ngành thực vật bậc cao có mạch; đó là: ngành Thông đất (Lycopodiophyta) có 3 loài thuộc 2 họ; ngành Dương xỉ (Polypodiophyta) có 20 loài thuộc 12 họ; ngành Thông (Pinophyta) có 6 loài thuộc 4 họ; ngành Mộc lan (Magnoliophyta) có 618 loài thuộc 119 họ (Bảng 3.1 và Hình 3.1).

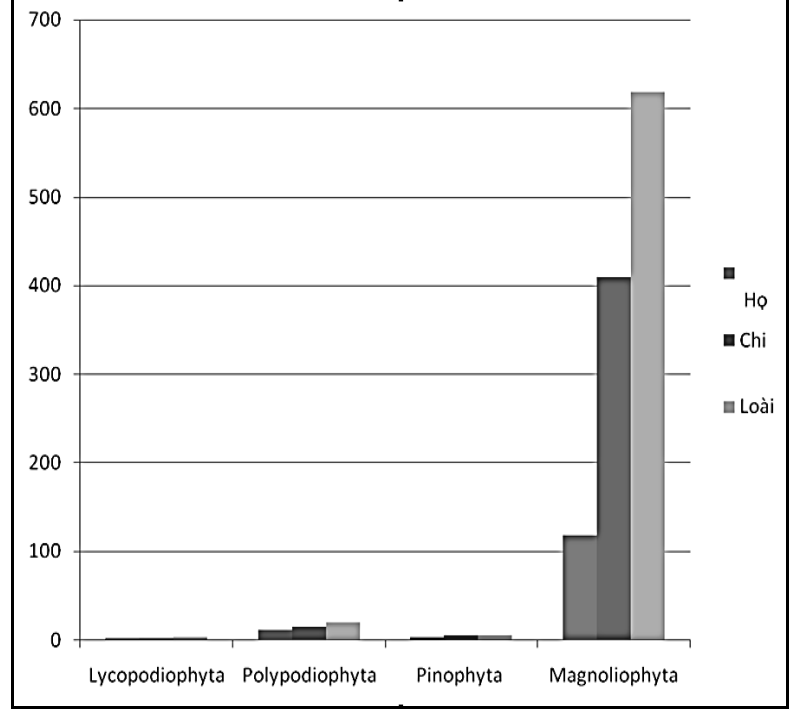

Hìn 3.1: Biểu đồ tỷ lệ số lương các ho và loài cây thuốc tại khu Bảo tồn thiên nhiên Na Hang

Bảng 3.1: Sụ phân bố cây thuốc của tùng ngành thực vật tại khu BTTN Na Hang, tỉnh Tuyên Quang

\begin{tabular}{|c|l|c|c|c|c|c|c|}
\hline \multirow{2}{*}{ STT } & \multirow{2}{*}{ Ngành } & \multicolumn{2}{|c|}{ Họ } & \multicolumn{2}{c|}{ Chi } & \multicolumn{2}{c|}{ Loài } \\
\cline { 3 - 8 } & & Số lượng & Tỷ lệ (\%) & Số lượng & Tỷ lệ (\%) & Số lượng & Tỷ lệ (\%) \\
\hline 1 & Lycopodiophyta & 2 & 1.46 & 2 & 0.46 & 3 & 0.46 \\
\hline 2 & Polypodiophyta & 12 & 8.76 & 15 & 3.46 & 20 & 3.09 \\
\hline 3 & Pinophyta & 4 & 2.92 & 6 & 1.39 & 6 & 0.93 \\
\hline 4 & Magnoliophyta & 119 & 86.86 & 410 & 94.69 & 618 & 95.52 \\
\hline & Tổng & $\mathbf{1 3 7}$ & $\mathbf{1 0 0 . 0 0}$ & $\mathbf{4 3 3}$ & $\mathbf{1 0 0 , 0 0}$ & $\mathbf{6 4 7}$ & $\mathbf{1 0 0 , 0 0}$ \\
\hline
\end{tabular}




\subsection{1. Đa dạng về các bậc taxon trong ngành}

Tính đa dạng của cây thuốc tại khu vực nghiên cứu không chỉ thể hiện ở số lượng lớn các taxon bậc ngành mà còn thể hiện ở sự phân bố của các bậc taxon trong các ngành khác nhau. Số lượng các taxon cụ thể trong từng ngành thực vật được trình bày cụ thể trong bảng 3.1.

Khi đi sâu nghiên cứu về thành phần cây thuốc tại khu BTTN Na Hang, thấy các taxon phân bố ở các ngành là không đều nhau.

Theo kết quả trình bày ở bảng 3.1 trên cho thấy: Ngành Mộc lan (Magnoliophyta) là ngành đa dạng nhất với 618 loài (chiếm 95,52\%) thuộc 410 chi (chiếm 94,69\%) và 119 họ (chiếm 86,86\%); kế tiếp là ngành Dương xỉ (Polypodiophyta) với 12 họ $(8,76 \%), 15$ chi (3,46\%), 20 loài (3,09\%); ngành Thông (Pinophyta) với 6 loài $(0,93 \%)$ thuộc 6 chi $(1,39 \%)$ và 4 họ $(2,92 \%)$; ngành Thông đất (Lycopodiophyta) có 3 loài thuộc 2 chi và 2 họ là ngành kém đa dạng nhất (chỉ chiếm $0,46 \%$ tổng số loài; $0,46 \%$ tổng số chi và $1,46 \%$ tổng số họ).
Ngành Mộc lan (Magnoliophyta) là ngành có số lượng về họ, chi và loài nhiều nhất trong khu vực nghiên cứu. Do vậy, đi sâu vào phân tích về tính đa dạng của các lớp trong ngành này. Ngành Mộc lan gồm có 2 lớp: Lớp Hành (Liliopsida) và lớp Mộc lan (Magnoliopsida). Trong đó, lớp Mộc lan chiếm ưu thế hơn hẳn với số họ là 94 (chiếm $78,99 \%$ ), số chi là 336 (chiếm $81,95 \%$ ) và số loài 505 loài (chiếm 81,72\%). Lớp Hành (Liliopsida) chiếm tỷ trọng thấp hơn hẳn, với số họ là 25 (chiếm $21,01 \%$ ), số chi là 74 (chiếm 18,05\%), số loài là 113 loài (chiếm 18,28\%) (Bảng 3.2). Theo kết quả thống kê ở bảng 3.2 cho thấy số lượng các taxon trong 2 lớp Mộc lan (Magnoliopsida) và Hành (Liliopsida) có sự khác biệt lớn. Tỷ lệ tương quan số loài giữa lớp Mộc lan và lớp Hành là 4,47; nghĩa là cứ 4,47 loài thuộc lớp Mộc lan thì có một loài thuộc lớp Hành. Tỷ lệ số chi giữa lớp Mộc lan và lớp Hành là 4,54; nghĩa là cứ 4,54 chi của lớp Mộc lan thì có 1 chi thuộc lớp Hành. Tỷ lệ giữa số họ giữa lớp Mộc lan và lớp Hành là 3,76 ; nghĩa là cứ 3,76 họ của lớp Mộc lan thì có 1 họ của lớp Hành.

Bảng 3.2: Phân bố các taxon (lớp, chi, loài) trong ngành Mộc lan (Magnoliophyta)

\begin{tabular}{|l|l|l|l|l|l|l|}
\hline \multirow{2}{*}{ Lớp } & \multicolumn{2}{c|}{ Họ } & \multicolumn{2}{c|}{ Chi } & \multicolumn{2}{c|}{ Loài } \\
\cline { 2 - 7 } & \multicolumn{1}{|c|}{ Số lượng } & \multicolumn{1}{c|}{ Tŷ lệ (\%) } & \multicolumn{1}{c|}{ Số lượng } & \multicolumn{1}{c|}{ Tỵ̂ (\%) } & \multicolumn{1}{c|}{ Số lượng } & Tỵ lệ) \\
\hline Magnoliopsida & 94 & 78.99 & 336 & 81.95 & 505 & 81.72 \\
\hline Liliopsida & 25 & 21.01 & 74 & 18.05 & 113 & 18.28 \\
\hline Tổng & $\mathbf{1 1 9}$ & $\mathbf{1 0 0 . 0 0}$ & $\mathbf{4 1 0}$ & $\mathbf{1 0 0 . 0 0}$ & $\mathbf{6 1 8}$ & $\mathbf{1 0 0 . 0 0}$ \\
\hline $\begin{array}{l}\text { Tỷ lệ Magnoliopsida } \\
\text { Liliopsida }\end{array}$ & 3.76 & 4.54 & 4.47 & \\
\hline
\end{tabular}

Bảng 3.3: Các chỉ số đa dạng của tùng ngành và của tổng cây thuốc tại khu BTTN Na Hang

\begin{tabular}{|c|l|l|l|l|l|l|l|}
\hline STT & \multicolumn{1}{|c|}{ Ngành } & \multicolumn{2}{c|}{ Chỉ số họ } & \multicolumn{2}{c|}{ Chỉ số chi } & \multicolumn{2}{c|}{ Chỉ số chi/ho } \\
\hline 1 & Lycopodiophyta & 2 & 1.46 & 2 & 0.46 & 3 & 0.46 \\
\hline 2 & Polypodiophyta & 12 & 8.76 & 15 & 3.46 & 20 & 3.09 \\
\hline 3 & Pinophyta & 4 & 2.92 & 6 & 1.39 & 6 & 0.93 \\
\hline 4 & Magnoliophyta & 119 & 86.86 & 410 & 94.69 & 618 & 95.52 \\
\hline & Tổng CT NH & $\mathbf{4 , 7 2}$ & $\mathbf{1 , 4 9}$ & & $\mathbf{3 , 1 6}$ & \\
\hline
\end{tabular}

Bảng 3.4: Thống kê 10 họ đa dạng cây thuốc nhất tại khu BTTN Na Hang, tỉnh Tuyên Quang

\begin{tabular}{|c|l|l|c|c|c|c|}
\hline \multirow{2}{*}{ STT } & \multicolumn{2}{|c|}{ Tên họ } & \multicolumn{2}{c|}{ Loài } & \multicolumn{2}{c|}{ Chi } \\
\cline { 2 - 7 } & \multicolumn{1}{|c|}{ Tên khoa học } & Tên Việt Nam & Số lượng & Tỷ lệ (\%) & Số lượng & Tỷ lệ (\%) \\
\hline 1 & Asteraceae & Cúc & 32 & 4.95 & 22 & 5.08 \\
\hline 2 & Rubiaceae & Cà phê & 28 & 4.33 & 16 & 3.70 \\
\hline 3 & Euphorbiaceae & Thầu dầu & 26 & 4.02 & 19 & 4.39 \\
\hline 4 & Moraceae & Dâu tằm & 23 & 3.55 & 7 & 1.62 \\
\hline 5 & Cucurbitaceae & Bầu bí & 18 & 2.78 & 16 & 3.70 \\
\hline 6 & Verbenaceae & Cỏ roi ngựa & 18 & 2.78 & 8 & 1.85 \\
\hline 7 & Araceae & Ráy & 17 & 2.63 & 11 & 2.54 \\
\hline 8 & Zingiberaceae & Gừng & 16 & 2.47 & 6 & 1.39 \\
\hline 9 & Urticaceae & Gai & 15 & 2.32 & 8 & 1.85 \\
\hline 10 & Poaceae & Lúa & 12 & 1.85 & 11 & 2.54 \\
\hline \multicolumn{2}{|l|}{ Tổng mười họ chiếm $\mathbf{3 1 , 6 8 \%}$} & $\mathbf{5 0 \%}$ & $\mathbf{2 0 5}$ & $\mathbf{3 1 . 6 8}$ & $\mathbf{1 2 4}$ & $\mathbf{2 8 . 6 4}$ \\
\hline
\end{tabular}


Về các chỉ số đa dạng cây thuốc tại khu BTTN Na Hang, tỉnh Tuyên Quang

Phân tích cây thuốc tại khu BTTN Na Hang, thu được các kết quả: chỉ số họ là: 4,72 (trung bình mỗi họ có gần 5 loài); chỉ số chi là 1,49 (trung bình mỗi chi có 1,5 loài); chỉ số chi trên chỉ số họ là 3,16 (trung bình mỗi họ có trên 3 chi).

\subsection{2. Đa dạng về bậc ho}

Qua quá trình nghiên cứu, đã xác định được 137 họ thực vật tại khu BTTN Na Hang, Tuyên Quang với 647 loài cây làm thuốc.

Mức độ đa dạng của mỗi hệ thực vật nói chung và cây thuốc nói riêng còn được nhìn nhận ở các cấp độ dưới ngành, cụ thể là cấp độ họ, chi và loài.

Đa dạng bậc họ, người ta thường phân tích 10 họ thực vật có số loài lớn nhất khu vực nghiên cứu (Bảng 3.4). Tại khu BTTN Na Hang, 10 họ giàu loài cây thuốc nhất chỉ chiếm 7,30\% tổng số họ cây thuốc; với tổng số loài chiếm $31,68 \%$ loài và chiếm $28,64 \%$ tổng số chi của toàn

Hình 3.2: 10 ho giàu loài cây thuốc nhất tại khu BTTN Na Hang, tỉnh Tuyên Quang

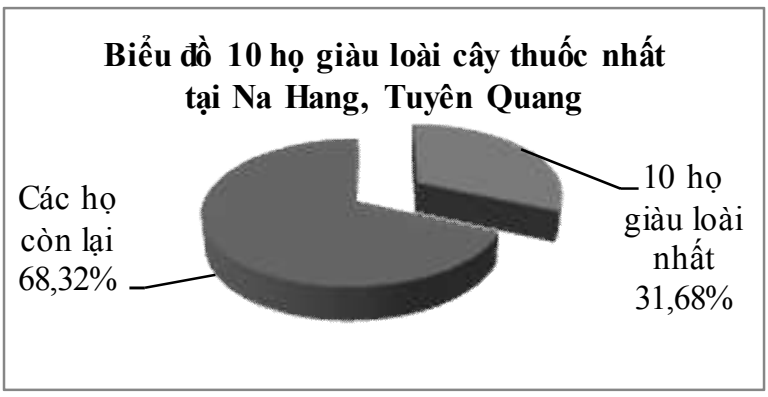

\subsection{3. Đa dạng về bậc chi}

Cây thuốc ở khu BTTN Na Hang phân bố trong 433 chi. Khi xét đến mức đa dạng chi, người ta thường xét 10 chi giàu loài nhất và sử dụng chỉ số đa dạng của tổng số chi so với tổng số họ và tổng số loài so với số chi của khu vực nghiên cứu. Áp dụng cách tính này cho số liệu ở bảng 3.5 , ta thấy rằng sự phân bố các loài cây trong các chi là không đều nhau; chi nhiều loài nhất gồm 15 loài (Ficus), chi có ít loài nhất chỉ có 1 loài (Lycopodium, Duabanga, Manglietia, Costus...). Chính vì vậy, 10 chi có số loài nhiều nhất được chọn ra để đánh giá mức độ đa dạng bậc bộ cây thuốc tại khu vực (Bảng 3.4, Hình 3.2). Họ có số loài nhiều nhất là họ Cúc (Asteraceae) với 32 loài, chiếm $4,95 \%$ tổng số loài cây thuốc ghi nhận được; tiếp theo là họ Cà phê (Rubiaceae) với 28 loài, chiếm 4,33\%, theo sau là họ Thầu dầu (Euphorbiaceae) 26 loài, chiếm 4,02\%; họ Dâu tằm (Moraceae) 23 loài, chiếm 3,55\%; họ Bầu bí (Cucurbitaceae); họ Cỏ roi ngựa (Verbenaceae) đều có số loài là 18 , chiếm $2,78 \%$ tổng số loài; tiếp đến là họ Ráy (Araceae) có 17 loài chiếm 2,63\%; họ Gừng (Zingiberaceae) với 16 loài, chiếm 2,47\%; họ gai (Urticaceae) có 15 loài chiếm $2,32 \%$ và cuối cùng là họ Lúa (Poaceae) có số loài là 12 , chiếm 1,85\% trên tổng số loài.

Tại khu BTTN Na Hang, 10 họ cây thuốc giàu loài nhất đều thuộc các họ đa dạng nhất của hệ thực vật Việt Nam.Điều này cũng phù hợp với nhận định của Tolmachov A. L. (1974) khi nghiên cứu tính đa dạng.

Theo nhận định này thì thành phần cây thuốc ở khu BTTN Na Hang đa dạng bậc họ vì tổng số loài của 10 họ này chiếm $31,68 \%$ nhỏ hơn $50 \%$.

chi được thể hiện ở bảng 3.5 dưới đây. Tổng số 10 chi đa dạng nhất có 59 loài, chiếm $9,12 \%$ tổng số loài cây thuốc tại khu BTTN Na Hang thì chi Ficus (Moraceae) đa dạng nhất với 15 loài, chiếm 2,32\% tổng số loài. Các chi còn lại có từ 4 loài trở lên đến 7 loài.

\subsubsection{Nguồn gen cây thuốc quý hiếm cần đực bảo vệ}

Tại khu BTTN Na Hang, tỉnh Tuyên Quang có sự phân bố của 30 loài cây thuốc quý hiếm, có nguy cơ tuyệt chủng được ưu tiên bảo tồn (bảng 3.6). Cụ thể như sau:

Có 09 loài có tên trong Nhóm IIA thuộc NĐ 32/2006/NĐ-CP.

Có 23 loài có tên trong Sách đỏ Việt Nam (2007) Phần II - Thực vật (16 loài được xếp ở mức Sẽ bị nguy cấp - VU; 07 loài xếp ở mức Đang nguy cấp - EN);

Có 17 loài có tên trong Danh lục đỏ cây thuốc Việt Nam, 2006 (10 loài xếp ở mức Sẽ bị nguy cấp - VU; 6 loài xếp ở mức Đang nguy cấp - EN và 01 loài xếp ở mức Cực kỳ nguy cấp - CR);

Có 07 loài có tên trong Danh lục đỏ IUCN (2014) (06 loài xếp ở mức Ít bị nguy cấp, 01 loài xếp ở mức Sẽ nguy cấp).

Bảng 3.5: Các chi giàu loài cây thuốc nhất tại khu BTTN Na Hang

\begin{tabular}{|c|l|c|c|}
\hline STT & \multicolumn{1}{|c|}{ Tên chi/họ } & Số loài & Tỷ lệ (\%) \\
\hline 1 & Ficus/Moraceae & 15 & 2,32 \\
\hline 2 & Dioscorea/Dioscoreaceae & 7 & 1,08 \\
\hline 3 & Rubus/Rosaceae & 6 & 0,93 \\
\hline 4 & Polygonum/Polygonaceae & 6 & 0,93 \\
\hline 5 & Piper/Piperaceae & 5 & 0,77 \\
\hline 6 & Hedyotis/Rubiaceae & 4 & 0,62 \\
\hline 7 & Solanum/Solanaceae & 4 & 0,62 \\
\hline
\end{tabular}


N.T.Hai et al./No.06_September 2017|p.44-49

\begin{tabular}{|c|l|c|c|}
\hline 8 & Clerodendrum/Verbenaceae & 4 & 0,62 \\
\hline 9 & Elastostema/Urticaceae & 4 & 0,62 \\
\hline 10 & Ophiopogon/Convallariaceae & 4 & 0,62 \\
\hline & Tổng 10 chi đa dạng nhất & $\mathbf{5 9}$ & $\mathbf{9 , 1 2}$ \\
\hline
\end{tabular}

Bảng 3.6: Danh sách các loài cây thuốc quý hiếm tại khu vục nghiên cúu

\begin{tabular}{|c|c|c|c|c|c|c|}
\hline STT & Tên khoa học & $\begin{array}{c}\text { Tên } \\
\text { Việt Nam }\end{array}$ & $\begin{array}{c}\text { NĐ 32/ } \\
2006 / \\
\text { N Đ-CP } \\
\end{array}$ & $\begin{array}{l}\text { SĐVN } \\
(2007)\end{array}$ & $\begin{array}{l}\text { DLĐCTV } \\
\text { N (2006) }\end{array}$ & $\begin{array}{l}\text { IUCN } \\
(2014)\end{array}$ \\
\hline 1 & Aglaia odorata Lour. & Ngâu & & & & LR/NT \\
\hline 2 & $\begin{array}{l}\text { Aphanamixispolystachya (Wall.) R.N. } \\
\text { Parker }\end{array}$ & & & & & $\mathrm{LR} / \mathrm{LC}$ \\
\hline 3 & Ardisiasilvestris Pitard & Lá khôi & & VU & & \\
\hline 4 & Aristolochiaindica L. & Sơn địch & & VU & VU & \\
\hline 5 & Asarumbalansae Franch. & Tế tân & IIA & EN & $\mathrm{CR}$ & \\
\hline 6 & Asarumcauligerum Hance & Trầu tiên & IIA & VU & EN & \\
\hline 7 & Asarumglabrum Merr. & Hoa tiên & IIA & VU & & \\
\hline 8 & Balanophora laxiflora Hemsl. & Dương đài & & EN & VU & \\
\hline 9 & Canarium tramdenum Dai. \& Yakovl. & Trám đen & & VU & & \\
\hline 10 & Chukrasia tabularis A. Juss. & Lát hoa & & VU & & $\mathrm{LR} / \mathrm{LC}$ \\
\hline 11 & Codonopsis celebica (Blume) Thuan & Ngân đẳng đứng & & VU & VU & \\
\hline 12 & Codonopsis javanica (Blume) Hook.f. & Đảng sâm & IIA & VU & EN & \\
\hline 13 & $\begin{array}{l}\text { Cycas dolichophylla K. D. Hill, H. T. } \\
\text { Nguyen \& Phan K. Lộc }\end{array}$ & Thiên tuế & IIA & & & NT \\
\hline 14 & $\begin{array}{l}\text { Dacrycarpusimbricatus } \\
\text { Laub. }\end{array}$ & Thông nàng & & & VU & LC \\
\hline 15 & Dacrydiumelatum (Roxb.) Wall. & Hoàng đàn giả & & & VU & LC \\
\hline 16 & Dendrobiumdevonianum Paxt. & Phương dung & & EN & & \\
\hline 17 & Dendrobiumfimbriatum Hook. & Kim điệp & & VU & & \\
\hline 18 & Dioscoreacollettii Hook.f. & Từ cô let & & EN & VU & \\
\hline 19 & Disporopsislongifolia Craib & Hoàng tinh cách & IIA & VU & EN & \\
\hline 20 & Drynariabonii H. Christ. & Cốt toái bổ bon & & VU & VU & \\
\hline 21 & Embeliaparviflora Wall. ex A. DC. & Rè dẹt & & VU & VU & \\
\hline 22 & Fallopiamultiflora (Thunb.) Haraldson & Hà thủ ô đỏ & & VU & EN & \\
\hline 23 & $\begin{array}{l}\text { Fokieniahodginsii (Dunn) A. Henry \& H. } \\
\text { H. Thomas }\end{array}$ & Pơ mu & IIA & EN & EN & VU \\
\hline 24 & $\begin{array}{l}\text { Gymnostemmapentaphyllum (Thunb.) } \\
\text { Makino }\end{array}$ & Giảo cổ lam & & EN & VU & \\
\hline 25 & Melienthasuavis Pierre & Rau sắng & & VU & & \\
\hline 26 & Podophyllumtonkinensis Gagnep. & Bát giác lien & & EN & EN & \\
\hline 27 & Rauvolfiaverticillata (Lour.) Baill. & Ba gạc vòng & & VU & VU & \\
\hline 28 & Stephania japonica(Thunb.) Miers & Thiên kim đằng & IIA & & & \\
\hline 29 & Stephania rotunda Lour. & Bình vôi & IIA & & & \\
\hline 30 & Xylopiapierrei Hance & Giền trắng & & VU & & \\
\hline
\end{tabular}

Chú thich: NĐ 32/2006/NĐ-CP: IIA - Hạn chế khai thác, sứ dụng vì muc đích thương mai.

Sách Đỏ Việt Nam (2007): EN - Đang bị nguy cấp; VU - Sẽ nguy cấp.

Danh lục Đỏ cây thuốc (2006): EN - Đang bị nguy cấp; VU - Sẽ nguy cấp.

DLĐ của IUCN (2014): VU - Sẽ nguy cấp; LR - Ít nguy cấp (Lower risk;

LC - Ít lo ngại (Least concern); NT - sắp bị đe dọa (Near threatened)

\section{Kết luận}

1. Đã xác định 647 loài thực vật được ghi nhận sử dụng làm thuốc tại khu BTTN Na Hang, tỉnh Tuyên Quang, thuộc 137 họ, 04 ngành thực vật bậc cao có mạch, đó là: ngành Thông đất (Lycopodiophyta) có 3 loài thuộc 2 họ; Ngành Dương xỉ (Polypodiophyta) có 20 loài thuộc 12 họ; ngành Thông (Pinophyta) có 06 loài thuộc 04 họ; ngành Mộc lan (Magnoliophyta) có 618 loài thuộc 119 họ.

2. Về các chỉ số đa dạng cây thuốc tại khu BTTN Na Hang, tỉnh Tuyên Quang cho thấy: chỉ số họ là: 4,72 (trung bình mỗi họ có gần 5 loài); chỉ số chi là 1,49 (trung bình mỗi chi có 1,5 loài); chỉ số chi trên chỉ số họ là 3,16 (trung bình mỗi họ có trên 3 chi). 
3. Tại khu BTTN Na Hang, 10 họ giàu loài cây thuốc nhất chỉ chiếm 7,30\% tổng số họ cây thuốc; với tổng số loài chiếm $31,68 \%$ loài và chiếm $28,64 \%$ tổng số chi của toàn bộ cây thuốc tại khu vực. Họ có số loài nhiều nhất là họ Cúc (Asteraceae) với 32 loài, chiếm $4,95 \%$ tổng số loài cây thuốc ghi nhận được; tiếp theo là họ Cà phê (Rubiaceae) với 28 loài, chiếm 4,33\%, theo sau là họ Thầu dầu (Euphorbiaceae) 26 loài, chiếm 4,02\%; họ Dâu tằm (Moraceae) 23 loài, chiếm 3,55\%; họ Bầu bí (Cucurbitaceae); họ Cỏ roi ngựa (Verbenaceae) đều có số loài là 18 , chiếm $2,78 \%$ tổng số loài; tiếp đến là họ Ráy (Araceae) có 17 loài chiếm 2,63\%; họ Gừng (Zingiberaceae) với 16 loài, chiếm 2,47\%; họ gai (Urticaceae) có 15 loài chiếm 2,32\% và cuối cùng là họ Lúa (Poaceae) có số loài là 12 , chiếm $1,85 \%$ trên tổng số loài.

4. Tại khu BTTN Na Hang, 10 chi đa dạng nhất có 59 loài, chiếm $9,12 \%$ tổng số loài cây thuốc tại khu BTTN Na Hang thì chi Ficus (Moraceae) đa dạng nhất với 15 loài, chiếm 2,32\% tổng số loài. Các chi còn lại có từ 04 loài trở lên đến 07 loài.

5. Đã thống kê được sự phân bố của 30 loài cây thuốc quý hiếm, có nguy cơ tuyệt chủng được ưu tiên bảo tồn. Có 23 loài có tên trong Sách đỏ Việt Nam (2007) 16 loài được xếp ở mức Sẽ nguy cấp - VU; 07 loài xếp ở mức Đang nguy cấp - EN.Có 17 loài có tên trong Danh lục đỏ cây thuốc Việt Nam, 2006 (10 loài xếp ở mức Sẽ nguy cấp - VU; 6 loài xếp ở mức Đang nguy cấp - EN và 01 loài xếp ở mức Cực kỳ nguy cấp $\mathrm{CR}$ ). Có 07 loài có tên trong Danh lục đỏ IUCN (06 loài xếp ở mức Ít bị nguy cấp (LR); 01 loài xếp ở mức Sẽ nguy cấp (VU).

\section{TÀI LIÊUU THAM KHẢO}

1. Bộ Khoa học và Công nghệ, Viện Khoa học và Công nghệ Việt Nam (2007), Sách Đỏ Việt Nam. Phần II: Thực vật, Nxb Khoa học Tự nhiên và Công nghệ;
2. Bộ Nông nghiệp và Phát triển Nông thôn (2000), Tên cây rù̀ng Việt Nam, Nxb Nông nghiệp, Hà Nội;

3. Chính phủ nước CHXHCN Việt Nam (2006), Nghi định 32/2006/NĐ-CP của Chính phủ về quản lý thục vật rùng, động vật rù̀ng nguy cấp, quý hiếm;

4. Nguyễn Tập (2006), Danh lục đỏ cây thuốc Việt Nam; Tạp chí Dược liệu 3(10);

5. Nguyễn Nghĩa Thìn (1997), Các phưong pháp nghiên cúu đa dạng sinh học, Nxb Đại học Quốc gia Hà Nội;

6. Nguyễn Nghĩa Thìn (chủ biên), Đặng Quyết Chiến (2006), Đa dạng thực vật Khu bảo tồn thiên nhiên $\mathrm{Na}$ Hang, tỉnh Tuyên Quang, Nxb Nông nghiệp, Hà Nội;

7. Nguyễn Anh Tuấn, Trần Huy Thái (2012), Đặc điểm sinh thái và phân bố của loài biến hóa núi cao (Asarum balansae Franch.) tại Bản Bung, huyện Na Hang, tỉnh Tuyên Quang. Tạp chí Sinh học, 34(1): 75-81;

8. Nguyễn Anh Tuấn, Trần Huy Thái, Jenn-Che Wang, Chang-Tse Lu (2012), Bổ sung loài Asarum yunnanense T. Sugaw., Ogisu \& C. Y. Cheng (ho Mộc huoong Aristolochiaceae) cho hệ thưc vật Việt Nam. Tạp chí Sinh học, 34(4): 441-445;

9. UBND tỉnh Tuyên Quang (1994), Quyết định số 274/1994/QĐ-UBND ngày 9/5/1994 của Chủ tịch Uỷ ban nhân dân tỉnh Tuyên Quang về việc phê duyệt thành lập khu Bảo tồn thiên nhiên Na Hang, tỉnh Tuyên Quang;

10.Hill M. and Kemp N. (1996), Na Hang Nature Reserve, Ban Bung sector.Report 8.Site description and conservation evaluation. Frontier Vietnam, Environmental Research. Hanoi;

11. Hill M. and Kemp N. (1997), Na Hang Nature Reserve, Tat Ke sector. Report 9.Site description and conservation evaluation. Frontier Vietnam, Environmental Research. Hanoi;

12. IUCN (2014), The Red List of threatened species. World Conservation Press. 